\title{
Manajemen Irigasi Tradisional pada Sistem Subak Umaya di Desa Talibeng Kecamatan Sidemen Kabupaten Karangasem
}

\author{
WAHYUNI YUSMITA, I GEDE SETIAWAN ADI PUTRA, \\ I WAYAN BUDIASA
}

\author{
Program Studi Agribisnis, Fakultas Pertanian, Universitas Udayana \\ Jl. PB.Sudirman 80323 Denpasar \\ E-mail: wahyuni.yuni42@gmail.com \\ igedesetiawanadiputra@gmail.com
}

\begin{abstract}
Traditional Irrigation Management at Subak Umaya System at Talibeng Village, Sub-district of Sidemen, Karangasem
\end{abstract}

Subak Umaya has a traditional irrigation system of water distribution system called bumbung. Subak generally faces problems of land use, loss of Tri Hita Karana elements and limitations of water. It is interesting to examine these conditions amid the problems of Subak irrigation system. On the initial observation at Subak Umaya showed that not all members use bumbung. The aim of research was to find out the traditional irrigation systems and irrigation water distribution to each member in the Subak Umaya. Data were analyzed by descriptive qualitative method. The research results indicate that the distribution of water in the form of water control system by using a tube/bumbung and cakangan. The rights to water is based on the size of land area. The water needs is based on the cropping pattern of rice - crops - crops. Ngulungasep planting system. Subak implements the system of continuous flow and intermittent flow to water the plant. Conflict over water has never happened. Canals that are the responsibility of Subak begin from the tunnel after Yeh Masin river to tertiary canals. The rituals are held collectively and individually. Sources of funding come from active members and the government. The Subak structure are: pekaseh/ subak's chief, vice of pekaseh, secretary, treasurer, kelian tempek, and assistant to kelian tempek. Members who use bumbung are $18 \%$, and $82 \%$ were taking cakangan. Many members use cakangan for their leniency rules. The specialty of the bumbung is to prevent flooding, because it has a measurable hole. Subak Umaya is expected to save funds to repair the broken channel. Subak should provide intermittent water flow and reapply the bumbung system in order to grow rice simultaneously. Additionally, Subak may make strict rules regarding the use of langki and cakangan.

Keywords: Subak system, function of Subak, water distribution

\section{Pendahuluan}

\subsection{Latar Belakang}

Subak merupakan organisasi tradisional yang sudah ada sejak tahun 882 Masehi (Purwita dan Cantika dalam Sudarta, 2005). Subak tetap mampu 
mempertahankan eksistensinya hingga saat ini. Subak masih mempertahankan cara tradisional dalam menjalankan aktifitas bertani dan berorganisasi. Fokus utama subak adalah sistem irigasi dimana organisasi ini memiliki keunikan dan ciri khas dalam pendistribusian air irigasi pada setiap anggotanya agar adil, efektif dan tidak menyebabkan konflik antar anggota subak. Shusila (1987) menyebutkan ada dua jenis sistem pembagian air yang diterapkan subak di Bali, yaitu sistem tektek dan sistem bumbung.

Sudah 29 tahun berlalu sejak tahun 1987 dimana penelitian tentang sistem bumbung oleh Shusila dilakukan, dan selama periode tersebut banyak tantangan yang dihadapi subak dalam mempertahankan eksistensinya. Budiasa dkk (2015) menyatakan "berdasarkan data statistik tahun 2012, Provinsi Bali (terdiri lebih dari 563.666 ha) meliputi 81.744 ha $(14,5 \%)$ sawah yang diatur langsung oleh 1.548 sistem subak, 273.655 ha $(48,55 \%)$ lahan pertanian lain, dan 208.267 ha $(36,95 \%)$ bukan lahan pertanian. Selama periode 15 tahun ( 1997-2011), konversi pertahun diperkirakan 436,3 ha $(0,5 \%)$. Tiga urutan teratas dari sembilan kabupaten yang mengalami konversi lahan di Bali adalah Denpasar, Klungkung dan Buleleng dengan rata-rata konversi pertahun berturut-turut adalah 1,33\% (35 ha), 0,8\% (31 ha), dan 0,45\% (50 ha). Area yang tersisa pada tahun 2013 adalah 81.165 ha, masih dipergunakan untuk menanam padi di Bali."

Sutawan (2001) menyatakan tantangan-tantangan yang dihadapi subak adalah persaingan dalam pemasaran hasil-hasil pertanian yang semakin tajam, menciutnya areal persawahan beririgasi akibat alih fungsi, ketersediaan air semakin terbatas, kerusakan lingkungan khususnya pencemaran sumberdaya air, penyerahan kembali tanggung jawab pengelolaan jaringan irigasi kepada petani, dan berkurangnya minat pemuda untuk bekerja sebagai petani.

Melihat begitu banyak permasalahan yang dihadapi oleh subak saat ini, maka menarik untuk dilihat bagaimana kondisi subak yang memiliki ciri khas bangunan atau alat bagi air berupa bumbung yang pernah diamati oleh Sushila. Penelitian difokuskan pada satu subak yaitu, Subak Umaya Kabupaten Karangasem setelah dilaksanakan pengecekan lokasi terlebih dahulu. Subak Umaya Kabupaten Karangasem dipilih menjadi lokasi penelitian karena disana masih terdapat sistem bumbung, namun, ternyata tidak semua anggota subak menggunakan sistem bumbung. Hal tersebut menarik untuk diteliti lebih lanjut. Terutama mengenai manajemen irigasi tradisional dan pembagian air irigasi yang diterapkan di subak Umaya.

\subsection{Rumusan Masalah}

Bagaimana sistem irigasi tradisional di Subak Umaya dan bagaimana sistem pengaturan pembagian air kepada setiap anggota Subak Umaya 


\subsection{Tujuan Penelitian}

Tujuan penelitian ini adalah mengetahui sistem irigasi tradisional di Subak Umaya dan sistem pengaturan pembagian air kepada setiap anggota Subak Umaya

\section{Metode Penelitian}

\subsection{Lokasi dan Waktu Penelitian}

Lokasi penelitian ditentukan dengan menggunakan metode purposive, dengan pertimbangan lokasi yang dipilih memiliki sistem irigasi tradisional khususnya sistem bumbung. Penelitian ini dilakukan di Subak Umaya yang terletak di Desa Talibeng, Kecamatan Sidemen, Kabupaten Karangasem. Lokasi ini ditentukan sebagai lokasi penelitian berdasarkan catatan Jelantik Sushila tahun 1987 yang menyatakan bahwa Subak Umaya memiliki sistem pendistribusian air irigasi tradisional berupa Bumbung. Penelitian di Subak Umaya, dilakukan selama empat bulan. Penelitian mulai dilaksanakan pada bulan April 2016 dan berakhir pada bulan Juli 2016.

\subsection{Data dan Metode Pengumpulan Data}

Data dan metode pengumpulan data yang digunakan dalam penelitian ini adalah sebagai berikut :

\subsubsection{Data}

Lofland dalam Ibrahim (2015) mengklasifikasikan data menjadi dua yaitu data utama (primer) dan data tambahan (sekunder) :

1. Sumber data utama (primer) atau informan kunci dalam penelitian ini adalah I Gusti Ngurah Suarjana (pekaseh Subak Umaya), I Nyoman Muniarta (kelian Tempek Dulu), I Nengah Karmada (wakil pekaseh), I Nyoman Sutama (prajuru subak), I Made Sudiarta (anggota subak), Gusti Aji Mangku Rai (anggota subak), Mangku Wayan Kerta (anggota subak), Made Mudika (kelian Tempek Teben), I Made Masih (anggota subak), Bapak Kerta (anggota subak), dan I Gusti Made Raka (mantan anggota subak).

2. Sumber data tambahan (sekunder) dalam penelitian ini adalah berupa: 1) Wilayah atau wujud fisik Subak Umaya yang ada di Desa Talibeng, Kecamatan Sidemen, Kabupaten Karangsem; 2) Dokumen berupa awig-awig Subak Umaya; dan 3) Buku dan dokumen lain yang dapat memberikan informasi tambahan mengenai Subak Umaya.

\subsubsection{Metode pengumpulan data}

Adapun metode pengumpulan data yang digunakan dalam penelitian ini adalah sebagai berikut: teknik observasi, teknik wawancara mendalam atau wawancara tak terstruktur, teknik dokumentasi, dan teknik FGD (Focus Group Discussion) 


\subsection{Penentuan Informan Kunci}

Teknik penentuan sumber data dalam penelitian ini adalah non probability sampling khususnya purposive sampling dan snowball sampling. Peneliti menetapkan kelian Subak Umaya yaitu I Gusti Ngurah Suarjana sebagai informan kunci dalam penelitian ini berdasarkan teknik purposive sampling. Kelian Subak Umaya ditetapkan sebagai informan kunci karena menjadi penanggung jawab subak dan pasti memiliki informasi mengenai Subak Umaya. Snowball sampling digunakan untuk menelusuri sumber data lain yang mempunyai karakteristik yang sama sebagaimana dikehendaki dalam penelitian ini seperti I Nyoman Muniarta, I Nengah Karmada, I Nyoman Sutama, I Made Sudiarta, Gusti Aji Mangku Rai, Mangku Wayan Kerta, Made Mudika, I Made Masih, Kerta, dan I Gusti Made Raka. Mereka adalah prajuru Subak Umaya, petani atau anggota Subak Umaya, dan mantan anggota Subak Umaya.

\subsection{Keabsahan Data dan Teknik Pemeriksaan Keabsahan Data}

Satori dan Komariah (2014) menyatakan penelitian kualitatif dinyatakan absah apabila memenuhi kriteria keabsahan data, yaitu: keterpercayaan (credibility), keteralihan (transferability), kebergantungan (dependability), dan kepastian (confirmability).

\subsection{Analisis Data}

Analisis data yang digunakan dalam penelitian ini adalah analisis data deskriptif kualitatif. Aktivitas analisis data menurut Miles dan Huberman dalam Satori dan Komariah (2014) terdiri dari: reduksi data, penyajian data dan penarikan kesimpulan. Peneliti menerapkan langkah-langkah tersebut sebagai berikut, pertama peneliti menghimpun sebanyak mungkin data yang dapat digali dari informan kunci tentang Subak Umaya. Data tersebut ditulis dalam bentuk laporan atau data yang rinci. Laporan disusun berdasarkan data yang diperoleh direduksi, dirangkum, dan dipilih hal-hal yang pokok seperti sistem pengairan dan sistem pengaturan air irigasi Subak Umaya. Reduksi data dilakukan agar data yang disajikan tidak keluar dari fokus permasalahan. Kedua, data-data yang sudah diklasifikasi dalam aspek penelitian tersebut disajikan dalam bentuk uraian rinci sesuai aspek kajian dengan dilengkapi dengan kutipan dari beberapa literatur, tabel dan foto. Tabel dan foto berfungsi sebagai objek ataupun pendukung aspek kajian. Ketiga adalah penarikan simpulan yang didasarkan pada rumusan masalah dan hasil penelitian.

\section{Hasil dan Pembahasan}

\subsection{Struktur Organisasi Subak Umaya}

Subak Umaya dipimpin oleh Pekaseh Subak Umaya yaitu I Gusti Ngurah Suarjana. Pekaseh dalam menjalankan tugasnya dibantu oleh wakil pekaseh yaitu I Nengah Karmada, sekretaris I Nengah Subrata, dan bendahara I Ketut Sudarta. Pekaseh juga dibantu oleh kelian tempek yaitu, kelian Tempek Dulu adalah I Nyoman Muniarta dan kelian Tempek Teben adalah I Made Mudika. Kelian tempek juga dibantu oleh pembantu kelian tempek, untuk kelian Tempek Dulu dibantu oleh I Nyoman Sutama, I Nengah Karmada, dan I Gusti Aji Werti, sedangkan untuk kelian 
Tempek Teben dibantu oleh I Ketut Murja. Masing-masing kelian tempek memerlukan pembantu kelian tempek. Jumlah anggota Subak Umaya saat ini adalah 279 orang. Anggota tersebut terbagi dalam dua tempek. Jumlah anggota subak pada Tempek Dulu adalah 150 orang dan jumlah anggota subak pada Tempek Teben adalah 129 orang. Anggota subak berasal dari beberapa desa yaitu Desa Talibeng, Desa Delod Yeh, Desa Pacung, Desa Sari, Desa Sukahet, Desa Wangsian, Desa Tangkup dan Desa Telungah. Awig-awig Subak Umaya (TT) menjelaskan bahwa di Subak Umaya terdapat krama ngarep dan krama suwinih. Tempek Teben memiliki 21 orang krama ngarep (anggota aktif) sedangkan Tempek Dulu memiliki 39 orang krama ngarep, sisanya adalah krama suwinih (anggota pasif).

\subsection{Sistem Irigasi Subak Umaya}

Sutawan (1989) menyatakan sistem irigasi subak berkaitan erat dengan fungsi subak, Ada lima fungsi subak yaitu: pencarian dan pendistribusian air irigasi, manajemen konflik, operasi dan pemeliharaan saluran irigasi, upacara ritual keagamaan dan mobilisasi sumber daya. Adapun fungsi dan struktur Subak Umaya dijelaskan sebagai berikut.

\subsubsection{Pencarian dan pendistribusian air irigasi}

Subak Umaya menggunakan air irigasi yang berasal dari Sungai Yeh Unda. Air dari Sungai Yeh Unda dibendung di Bendungan Umaya dan Subdem. Air dari bendungan mengalir ke saluran primer yang berupa terowongan dan air dari subdem mengalir ke saluran terbuka (telabah). Air dari telabah dan terowongan bertemu pada satu saluran primer, hingga saluran tersebut sampai pada Sungai Yeh Pandan yang memutus saluran primer subak. Terdapat bendung kecil di Sungai Yeh Pandan yang berfungsi sebagai bangunan pelimpah samping keluar. Bendung kecil ini bertujuan agar air dari Sungai Yeh Unda dapat masuk ke saluran primer Subak Umaya yang selanjutnya. Saluran selanjutnya berupa terowongan sampai di sebelah utara Pura Bedugul. Saluran irigasi subak umaya sudah berupa telabah setelah terowongan. Saluran sekunder Subak Umaya berada ditengah-tengah subak. Air yang mengalir disaluran sekunder disadap terlebih dahulu ke saluran tersier. Anggota subak hanya diperbolehkan mengambil air dari saluran tersier untuk dialirkan kesawah individu.

Alokasi pembagian air di Subak Umaya menggunakan alat berupa langki/bumbung dan cakangan. Subak Umaya memiliki aturan, sawah yang letaknya dekat dengan saluran sekunder menggunakan alat berupa langki dan sawah yang letaknya ditengah atau jauh dari saluran sekunder menggunakan cakangan. Hak atas air di Subak Umaya didasarkan pada luas lahan. Luas lahan bulan tenah (rata-rata 0,25-0,30 ha) mendapatkan jatah air sebanyak 3 nyari/jari (kira-kira 5 x $5 \mathrm{~cm}$ ), luas lahan bulan sibak (rata-rata 0,15-0, 24 ha) mendapatkan jatah air 2 nyari/jari (kirakira $3 \times 3 \mathrm{~cm}$ ), dan luas lahan bulan depuk (rata-rata 0,10-0,14 ha) mendapatkan jatah air 1 nyari/jari (kira-kira 1,5 x 1,5 cm).

Peraturan tersebut berlaku ketika masa tanam padi. Kebutuhan air di Subak Umaya ditentukan oleh pola tanam. Pola tanam di Subak Umaya adalah sebagai berikut. 
Tabel 1.

Pola Tanam di Subak Umaya

\begin{tabular}{ccccccccccccc}
\hline \multirow{2}{*}{ Tempek } & \multicolumn{10}{c}{ Bulan } \\
\cline { 2 - 9 } & Jan & Feb & Mar & Apr & Mei & Jun & Jul & Agu & Sep & Okt & Nov & Des \\
\hline Dulu & & & & & & & & & & & & \\
\hline Teben & & & & & & & & & & & & \\
\hline
\end{tabular}

Keterangan tabel :

$$
\begin{aligned}
& =\text { Padi } \\
& =\text { Palawija umur pendek } \\
& =\text { Palawija umur panjang }
\end{aligned}
$$

Tabel tersebut memberikan gambaran pola tanam Subak Umaya yaitu padipalawija-palawija. Tabel diatas juga memberikan informasi mengenai sistem penanaman padi yang digunakan di Subak Umaya yaitu ngulu-ngasep. Penerapan sistem penanaman ngulu-ngasep di Subak Umaya sedikit berbeda yaitu bagian hilir atau Tempek Teben yang diberikan air terlebih dahulu. Tempek Dulu mendapatkan air dan mulai dapat mengolah tanah setelah tanaman padi di Tempek Teben tidak membutuhkan banyak air. Penerapan sistem ngulu-ngasep seperti diatas memungkinkan setiap tempek dapat merasakan musim hujan pada saat tanam padi.

Pada saat menanam palawija anggota subak memberikan air secara terputusputus, Huda (2012) memberikan istilah intermitten flow. Anggota Subak Umaya memberikan air pada tanaman padi secara terus-menerus, ketika debit air mencukupi ataupun dalam kondisi surplus. Huda (2012) memberikan istilah pemberian air secara terus menerus yaitu continus flow Pemberian air secara intermitten flow dilakukan jika terjadi kondisi seperti kerusakan kempelan dan kekurangan air pada musim kemarau baik untuk tanaman padi ataupun palawija.

\subsubsection{Manajemen konflik}

Selama ini perselisihan akibat perebutan air belum pernah terjadi. Selama ini anggota subak dapat mengatur kebutuhan air masing-masing. Anggota subak memiliki tenggang rasa yang tinggi dalam pengaturan air, sehingga konflik dapat dihindari. Anggota subak akan menegur anggota lain bila yang bersangkutan mengambil air melebihi jatah yang sudah ditentukan. Biasanya dengan teguran saja anggota subak sudah mengerti kesalahannya dan mengatur kembali saluran inletnya. Pelanggaran terhadap tataguna air sudah diatur dalam awig-awig. 


\subsubsection{Operasi dan pemeliharaan saluran irigasi}

Subak Umaya melaksanakan pembersihan dan pengecekan saluran pada saat akan menanam padi. Biasanya pembersihan saluran dilaksanakan dua kali dalam setahun. Pembersihan dan pengecekan saluran dilakukan oleh krama ngarep. Krama ngarep yang bertugas tergantung pada tempek mana yang akan menanam padi.

\subsubsection{Upacara ritual keagamaan}

Upacara ritual keagamaan yang dilaksanakan secara kolektif adalah: matur piuning, magpag toya, ngendangin, peneduhan, meayu-ayu, ngulanin atau ngenteg sari, dan ngerasakin. Anggota Subak Umaya juga melaksanakan ritual secara individu yaitu: peneduhan di sawah pribadi, biu kukung, ngalapain atau nyaupin, dan mantenin.

\subsubsection{Mobilisasi sumber daya}

Subak memerlukan sejumlah dana untuk melakukan perbaikan dan pemeliharaan terhadap fasilitas yang dimiliki (Windia, 2006). Sumber dana Subak Umaya berasal dari peturunan (sejumlah dana yang harus dibayarkan ke subak) yang dibayarkan oleh krama ngarep (anggota aktif) dan bantuan pemerintah. Pemerintah memberikan bantuan dana setiap tahun sejak 2006. Tahun 2015 untuk pembangunan fisik subak mendapat dana 35.750.000 dari provinsi dan dari kabupaten Karangasem memberikan Rp 3.000.000. Subak mendapat bantuan dana dengan jumlah yang sama pada tahun 2016. Subak harus aktif dalam membuat proposal untuk mendapat bantuan. Dana tersebut bisa dipergunakan untuk perbaikan fisik misalnya perbaikan pura subak, perbaikan saluran irigasi, pembuatan jalan usaha tani, dan penyelenggaraan ritual yang diperlukan oleh subak secara kolektif.

\subsection{Pengaturan Pembagian Air}

Pembagian air pada Subak Umaya di dasarkan pada luas lahan. Kewajiban anggota subak ditentukan oleh luas lahan dan bagian air yang diterima. Pembagian air dahulu dan sekarang memiliki perbedaan. Dahulu, semua anggota subak diwajibkan menggunakan bumbung atau biasa disebut langki. Langki menggunakan ukuran jari/nyari. Ukuran pemberian air didasarkan pada luas lahan anggota subak. Luas lahan bulan tenah rata-rata 0,25-0,30 Ha mendapat jatah 3 jari/nyari, luas lahan bulan sibak rata-rata 0,15-0,24 Ha mendapat jatah air 2 jari/nyari, dan bulan depuk yang luas lahannya rata-rata 0,10-0, 14 Ha mendapat jatah air 1 nyari/jari.

Bumbung atau yang biasa disebut langki oleh anggota Subak Umaya adalah bangunan inlet yang digunakan untuk mengalirkan air ke petak sawah. Langki terbuat dari ruas bambu yang panjangnya kira-kira 50-60 $\mathrm{cm}$ dengan diameter ratarata $7 \mathrm{~cm}$. Bambu tersebut dihilangkan salah satu sekatnya sebagai jalan masuk air. Sekat lainnya tetap dibiarkan utuh. Lubang berbentuk persegi dibuat sebagai jalan keluar air. Lubang persegi tersebut terletak beberapa $\mathrm{cm}$ dari sekat yang tertutup. 
Langki diletakkan di cakangan (saluran inlet), bagian yang berlubang ditancapkan di cakangan sebagai jalan masuk air. Lubang persegi diletakkan menghadap kesawah dengan posisi lubang menghadap keatas. Keistimewaan langki/bumbung adalah sebagai berikut: mencegah terjadinya banjir ketika musim hujan karena memiliki lubang yang terukur sehingga debet air yang masuk tetap, dapat mengurangi masuknya pasir ke areal sawah dan dapat menghalangi sampah masuk ke areal sawah dengan satu alat, memiliki ukuran aturan yang pasti sehingga mudah untuk diawasi dan anggota sulit untuk melakukan kecurangan dalam pendistribusian air irigasi. Contoh bumbung dapat dilihat pada gambar 1 .

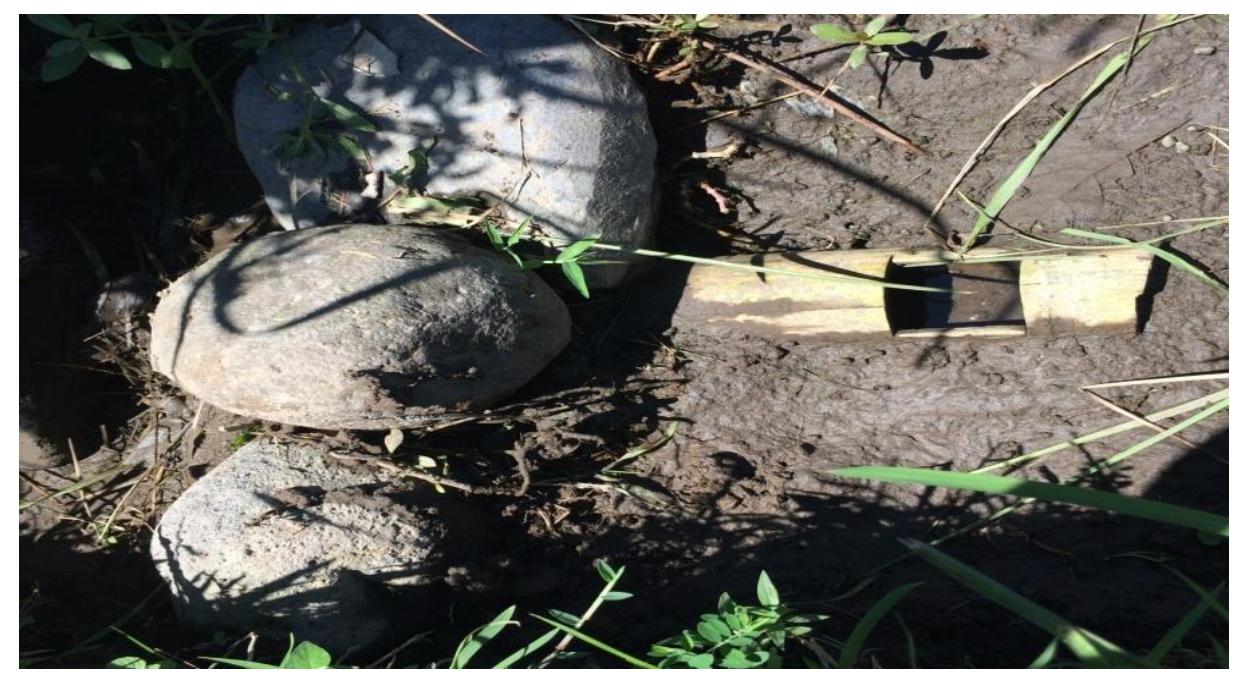

Gambar 1. Langki atau Bumbung

Saat ini lahan dengan luas bulan tenah (0,25-0,30 ha) mendapat bagian air 3 nyari/jari (kira-kira 5 x $5 \mathrm{~cm}$ ), lahan dengan luas bulan sibak (0,15-0,24 ha) mendapat bagian air 2 nyari/jari (kira-kira $3 \times 3 \mathrm{~cm}$ ), lahan dengan luas bulan depuk (0,10-0,14 ha) mendapat bagian air 1 nyari/jari (kira-kira 1,5 x 1,5 cm). Aturan tersebut berlaku baik bagi anggota yang menggunakan langki ataupun cakangan. Anggota Subak Umaya saat ini ada yang menggunakan cakangan ada juga yang memakai langki. Cakangan adalah saluran inlet berupa lubang yang dibuat untuk mengalirkan air ke petak sawah. Lubang tersebut bisa terbuka maupun tertutup. Cakangan dengan lubang tertutup biasanya dibuat saat anggota subak menggunakan langki, sedangkan jika anggota subak tidak menggunakan langki maka cakangan dibuat terbuka.

Bentuk dan aturan pengunaan langki sekarang tidak jauh berbeda dengan dahulu. Perbedaannya terletak pada penerapan aturan dalam pembagian air irigasi di Subak Umaya. Dahulu, anggota subak sangat tertib dalam mengikuti aturan yang berlaku. Berbeda dengan saat ini, dari observasi yang dilakukan di Subak Umaya terlihat anggota subak tidak tertib dalam menerapkan aturan. Hal tersebut terbukti dengan penemuan langki dengan dua lubang persegi. Pada saat observasi, ditemukan langki dengan satu lubang persegi sebagai jalan keluar air dan dua lubang persegi 
sebagai jalan keluar air. Langki dengan satu lubang persegi sebagai jalan keluar air memiliki diameter bambu $7 \mathrm{~cm}$ dan luas lubang perseginya 7 x $7 \mathrm{~cm}$. Langki yang memiliki dua lubang persegi sebagai jalan keluar air, masing-masing lubangnya memiliki luas 4 x $4 \mathrm{~cm}$, diameter $7 \mathrm{~cm}$ dan panjangnya $19 \mathrm{~cm}$. Subak Umaya dalam penerapan aturan saat ini tidak ketat seperti dahulu. Hal tersebut mengakibatkan anggota subak cenderung lebih memilih menggunakan cakangan yang bisa langsung mengalirkan air lebih banyak dan lebih cepat.

Kelonggaran aturan ini disebabkan Subak Umaya sudah memiliki bendung dan subdem serta saluran primernya sebagian sudah permanen. Adanya bangunan permanen tersebut membuat debit air yang masuk ke Subak Umaya lebih besar dari sebelumnya. Faktor lain yang menyebabkan terjadinya kelonggaran dalam penerapan aturan yaitu, masa tanam padi dibedakan antara Tempek Dulu dan Tempek Teben. hal tersebut menyebakan ketersediaan air berlimpah untuk sekali masa tanam padi di satu tempek. Kelebihan air tersebut dapat dimanfaatkan oleh anggota subak dengan memperlebar bangunan sadapnya sesuai kebutuhan. Disini terdapat kontrol kearifan lokal dari anggota subak. Kearifan lokal tersebut adalah setiap anggota subak mengontrol sendiri kebutuhan air irigasinya agar sesuai dengan kebutuhan tanaman dan agar anggota subak yang lain mendapat bagian air. Saat ini sudah sedikit anggota subak yang masih menggunakan sistem bumbung. Anggota subak yang memakai bumbung berjumlah 50 orang atau sekitar $18 \%$ dari keseluruhan, sedangkan $82 \%$ atau 229 anggota subak lainnya menggunakan cakangan. Contoh cakangan dapat diliat pada gambar 2 .

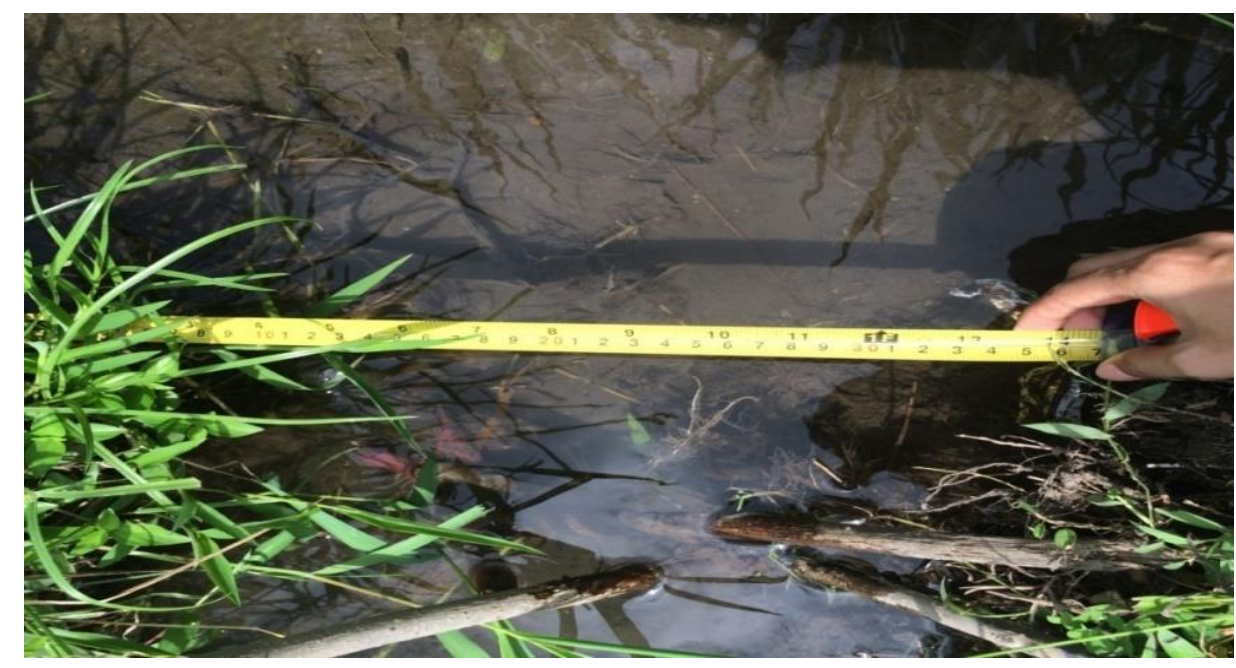

Gambar 2. Cakangan

\section{Simpulan dan Saran}

Berdasarkan hasil dan pembahasan dapat disimpulkan sebagai berikut:

1. Pembagian air di subak menggunakan alat berupa bumbung dan cakangan. Hak atas air didasarkan pada luas lahan yaitu luas lahan bulan tenah (rata-rata 0,250,30 ha) mendapatkan jatah air sebanyak 3 nyari/jari (kira-kira 5 x $5 \mathrm{~cm}$ ), luas 
lahan bulan sibak (rata-rata 0,15-0, 24 ha) mendapatkan jatah air 2 nyari/jari (kira-kira 3 x $3 \mathrm{~cm}$ ), dan luas lahan bulan depuk (rata-rata 0,10-0,14 ha) mendapatkan jatah air 1 nyari/jari (kira-kira $1,5 \times 1,5 \mathrm{~cm}$ ). Kebutuhan air berdasarkan pola tanam padi-palawija-palawija. Sistem penanaman yang diterapkan adalah ngulu-ngasep. Subak menerapkan sistem continues flow pada tanaman padi saat air mencukupi dan intermitten flow untuk palawija dan padi ketika sulit air. Konflik akibat air belum pernah terjadi karena adanya tenggang rasa dan awig-awig yang mengatur. Saluran yang menjadi tanggung jawab subak dimulai dari trowongan setelah Sungai Yeh Masin sampai ke saluran tersier dimana pemeliharaannya dilakukan setiap tanam padi oleh tempek yang bersangkutan. Upacara ritual dilaksanakan secara kolektif dan individu. Sumber dana berasal dari anggota aktif dan pemerintah.

2. Struktur subak: pekaseh, wakil pekaseh, sekretaris, bendahara, kelian tempek, dan pembantu kelian tempek.

3. Anggota yang memakai bumbung 18\%, dan $82 \%$ memakai cakangan. Banyak anggota menggunakan cakangan karena adanya kelonggaran dalam penerapan aturan pembagian air. Keistimewaan bumbung adalah mencegah terjadinya banjir, karena memiliki lubang yang terukur.

Subak umaya diharapkan dapat merevitalisasi aturan mengenai alokasi dan pendistribusian air irigasi agar tidak terjadi konflik dimasa depan.

\section{Ucapan Terimakasih}

Ucapan terimakasih kepada pekaseh, prajuru dan anggota Subak Umaya yang sudah membantu dalam pelaksanaan penelitian. Ucapan terimakasih juga disampaikan kepada dosen-dosen yang telah membantu menyelesaikan e-jurnal ini.

\section{Daftar Pustaka}

Awig-Awig Subak Umaya. TT. Awig-Awig Subak Umaya Pasedahan Yeh Unda Teben Desa Talibeng Kecamatan Sidemen Kab. Dati. II Karangasem. Karangasem

Budiasa, I Wayan, B.I Setiawan, H. Kato, N. Sekino, J. Kubota. 2015. The Role of The Subak System and Tourism on Land Use Changes Withen the Saba Watershed, Northern Bali, Indonesia. Indonesia. J.ISSAS Vol. 21, No. 2 (3147).

Huda, Nurul M, Donny.H dan Dwi.P. 2012. Kajian Sistem Pemberian Air Irigasi Sebagai Dasar Penyusunan Jadwal Rotasi Pada Daerah Irigasi Tumpang Kabupaten Malang. Jurnal Teknik Pengairan. Volume 3 No 2 Desember 2012. Hlm 221-229.

Ibrahim. 2015. Metodologi Penelitian Kualitatif Panduan Penelitian Beserta Contoh Proposal Kualitatif. Bandung: Alfabeta.

Satori, Djam'an dan A. Komariah. 2014. Metodologi Penelitian Kualitatif. Bandung: Alfabeta.

Sudarta,Wayan. 2005. Beragam Nilai Tradisional Subak (Konsep yang Relevan dengan Inovasi). Yogyakarta: Andi Offset 
Sushila, Jelantik. 1987. Ciri-Ciri Khas dari Subak Sistem Irigasi di Bali. Denpasar: Sub Dinas Pengairan Dinas Pekerjaan Umum Provinsi Daerah Tingkat I Bali.

Sutawan. 1989. Farmer-Managed Irrigation Systems and the Impact of Government assistance: A Note From Bali Indonesia. Sri Lanka: International Irrigation Management Institute

Sutawan, Nyoman. 2001. Eksistensi Subak di Bali: Mampukah Bertahan Menghadapi Berbagai Tantangan. Artikel online [http://download.portalgaruda.org/article.php?article=12877\&val=926]. Diakses tanggal, 11 Agustus 2016

Windia, Wayan. W. Sudarta dan WS. Astiti. 2015. Sistem Subak di Bali Kajian Sosiologis. Denpasar: Udayana University Press 